\title{
O Sujeito Lúdico Produzido pela/na Educação Matemática: Interlocuções com o neoliberalismo*
}

\author{
The Playful Subject Produced in/through Mathematics Education: \\ Interlocutions with Neoliberalism
}

\author{
Alice Stephanie Tapia Sartori** \\ Claudia Glavam Duarte ${ }^{* * *}$
}

\begin{abstract}
Resumo
Este artigo tem como objetivo problematizar o uso de atividades lúdicas propostas para o ensino de matemática, entendendo a escola como um espaço de formação de subjetividades. O foco de nossa análise volta-se para o sujeito produzido pelo discurso lúdico e suas interlocuções com o neoliberalismo, com base nos estudos de Michel Foucault e de seus comentadores. A partir da Análise do Discurso na perspectiva deste filósofo, analisamos trabalhos publicados nos anais do XI Encontro Nacional de Educação Matemática. As enunciações que destacamos apontam para possíveis entrelaçamentos entre as práticas lúdicas e as características estabelecidas pelo neoliberalismo, como a capacidade de construir suas próprias ideias, pensar de forma independente, ser ativo na construção do conhecimento, ter autoconfiança, ser empreendedor de si mesmo, ter liberdade para tomar decisões, competir e ser um sujeito consumidor. Esta análise nos permitiu outro olhar sobre as verdades naturalizadas, as práticas e as pesquisas no campo da Educação Matemática.
\end{abstract}

Palavras-chave: Educação Matemática. Sujeito Lúdico. Neoliberalismo.

\begin{abstract}
This article aims to discuss the use of playful activities proposed for teaching mathematics, having the school as a training space of subjectivities. The focus of our analysis turns to the subject produced by the playful discourse and its interlocution with neoliberalism, based in studies of Michel Foucault and his commentators. From the Discourse Analysis in the perspective of this philosopher, we analyzed XI ENEM's annals (National Meeting of Mathematics Education) published studies. The statements that we highlight point to possible interweavings between the playful practices and the characteristics of neoliberalism, as the ability to build their own ideas, or think independently, be active in the construction of knowledge, have confidence, be an entrepreneur of himself, having freedom to make decisions, compete and be a consumer subject. This analysis allowed us to another look at the naturalized truths, practices, and research in the field of Mathematics Education.
\end{abstract}

Keywords: Mathematics Education. Playful Subject. Neoliberalism.

\footnotetext{
* Este texto é uma versão expandida da comunicação científica intitulada Incursões foucaultianas para pensar o lúdico no ensino de Matemática e a governamentalidade neoliberal, apresentada na VI Jornada Nacional de Educação Matemática, ocorrida em maio de 2016.

** Doutoranda em Educação Científica e Tecnológica pela Universidade Federal de Santa Catarina (UFSC). Endereço para correspondência: Rua Nossa Senhora do Rosário, $\mathrm{n}^{\circ}$ 20, ap. 402, Jardim Atlântico, Florianópolis/SC, CEP: 88095-250. E-mail: alice.stephanie.ts@gmail.com.

*** Doutora em Educação pela Universidade do Vale do Rio dos Sinos (UNISINOS). Professora do curso de Licenciatura em Educação do Campo da Universidade Federal do Rio Grande do Sul (UFRGS) - Campus Litoral, Tramandaí/RS, Brasil. Endereço para correspondência: Travessa Sapiranga, $\mathrm{n}^{\circ}$ 1275, Centro, Tramandaí/RS, CEP: 95590-000. E-mail: claudiaglavam@ hotmail.com.
} 


\section{A escola-empresa fabricando o sujeito-cliente}

[...] entender como o mundo está se constituindo e permanentemente se reconstituindo, como os modos de governar os outros e a si mesmo estão se modificando, parece-nos de grande relevância para (re)pensarmos tanto as práticas escolares quanto as teorizações educacionais a elas relacionadas (SARAIVA; VEIGA-NETO, 2009, p. 200).

Pensar a Educação Matemática na contemporaneidade requer de nós, educadores e pesquisadores deste campo, refletir sobre as mudanças que vem ocorrendo em nossa sociedade, as novas formas de governo e as relações de poder que se estabelecem não somente na instituição escolar. É nesta conjuntura que este estudo se insere, pois percebemos a escola, especialmente as aulas de Matemática, como espaço de formação de subjetividades. Deste modo, cabe inicialmente enfatizar que o sujeito produzido pela escola, de que tratamos neste estudo, não é o sujeito cognitivo, mas um indivíduo produzido pelo saber.

O foco de nossa análise é a constituição do sujeito lúdico, entendido como efeito das linhas de enunciação e de força da sociedade neoliberal. Fazemos esta reflexão a partir da análise do discurso na perspectiva foucaultiana, entendendo que o discurso, como forma de saber que afirma a importância da utilização de atividades lúdicas nas aulas de Matemática, produz um sujeito lúdico. Neste sentido, entendemos o discurso ora como campo de saber, ora combinado com o poder. A interlocução do discurso lúdico com aspectos da sociedade neoliberal é sugerida a partir da análise dos anais do XI Encontro Nacional de Educação Matemática (ENEM). Propomos estes entrelaçamentos à luz dos estudos de Michel Foucault e de seus comentadores, especialmente aqueles que dialogam com o campo da Educação.

Veiga-Neto (2000) é um destes autores que buscou analisar as intensas transformações que vem ocorrendo em nossa sociedade nas últimas décadas e suas relações com a escola, como a globalização da economia, a concentração de renda nos países ricos, o aparecimento de minorias (étnicas, sexuais, religiosas, culturais, etc.) e o surgimento e expansão do neoliberalismo. Como sugere o autor, a escolarização é importante e até mesmo crucial para a lógica neoliberal. Em termos foucaultianos, podemos designar o neoliberalismo como uma prática ou como uma forma de governar na contemporaneidade.

Foucault interessou-se pela questão do governo dos homens, mostrou novas maneiras de se pensar a política e desenvolveu uma análise histórica das práticas de governar. Neste contexto, o filósofo elaborou uma de suas principais ferramentas conceituais, empreendida como um conjunto que inclui tais práticas de governo, denominado de governamentalidade. 
Segundo Foucault (1992), desde o século XVIII vivemos a era da governamentalidade. Ao explicar a formulação deste termo, o filósofo afirma:

Por 'governamentalidade' entendo o conjunto constituído pelas instituições, procedimentos, análises e reflexões, cálculos e táticas que permite exercer esta forma bastante específica e complexa de poder, que tem por alvo a população, por forma principal de saber a economia política e por instrumentos técnicos essenciais os dispositivos de segurança (FOUCAULT, 1992, p. 291).

A análise da governamentalidade compreende o exame do que Foucault chamou de "artes de governar" ou as diversas práticas de governo e a imanência dessas práticas em relação ao Estado. Para a lógica neoliberal, por exemplo, é necessária a intervenção do Estado sob a população para que se possa garantir que o mercado a regule. Neste contexto, é possível observar que tipo de sujeito o neoliberalismo está interessado em produzir a partir da governamentalidade neoliberal.

A ênfase na lógica neoliberal passa a ser o produto ao invés da produção, e sua circulação depende do mercado, por meio dele a sociedade é regrada economicamente e se instaura uma ordem social. Assim, torna-se necessário preparar consumidores para que estejam receptivos a tais mudanças, de forma que sejam produzidos como Homo Manipulabilis e não mais como Homo Economicus como no liberalismo.

\begin{abstract}
Enquanto o liberalismo situa o "homem econômico" como um "homem de troca", o neoliberalismo se esforça em assegurar que os indivíduos são obrigados a assumir valores baseados no mercado em todos os seus julgamentos e práticas para reunir quantidade suficiente de "capital humano" e assim tornarem-se "empreendedores de si” (HAMANN, 2012, p. 101).
\end{abstract}

Deste modo, podemos constatar a valorização da empresa para a economia, considerada uma necessidade para o funcionamento do Estado. Esta outra arte de governar que vem sendo designada de "capital humano" objetiva constituir sujeitos capacitados para serem empreendedores de si mesmos (COSTA, 2009), sujeitos materialistas, individualistas e autônomos. Tal perspectiva aponta para uma produção da sociedade submetida à concorrência e não mais à mercadoria, pois está tornando-se uma sociedade empresarial. Neste contexto, para estabelecer a lógica neoliberal são necessários sujeitos produtores e também consumidores, que estão constantemente em busca de novos desafios e metas a serem superadas.

Costa (2009), ao pensar sobre os efeitos ou desdobramentos da cultura do empreendedorismo no campo da Educação aponta que, uma das expressões do exercício do que Foucault chama de governamentalidade neoliberal é a exigência do novo capitalismo de potencializar a individuação de cada um. Essa nova lógica vislumbra a produção de um 
"indivíduo-micro-empresa", conduzidos por uma normatividade econômico-empresarial. Esses sujeitos "são caracterizados pelos seguintes traços: são proativos, inovadores, inventivos, flexíveis, com senso de oportunidade, com notável capacidade de provocar mudanças, etc.” (p. 180). A pedagogia nesta perspectiva incentiva o individual e o processo de aprender a aprender que são considerados mais importantes do que o trabalho em equipe e o ensino, e devem voltar-se, sobretudo, para a inovação (COSTA, 2009).

Considerando as tecnologias de poder envolvidas para constituir este sujeito necessário à governamentalidade neoliberal, Veiga-Neto (2000) destaca a maximização da liberdade individual: são oferecidas infinitas possibilidades de escolha ao sujeito-cliente, visto como portador de uma faculdade humana fundamental, a capacidade de escolher. Para que ocorra esta liberdade de escolha o sujeito deve aprender a fazê-las combinando múltiplos critérios. Assim, o sujeito neoliberal precisa desenvolver a capacidade de saber escolher o que é melhor para si, deve ser o empresário de si mesmo. Liberdade neste cenário é uma condição essencial para a construção de um sujeito de desejo, de interesses, de escolha. O sujeito deve ser antes conformado, guiado e moldado para ser responsável pela sua própria liberdade (VEIGA-NETO, 2000).

Além disso, torna-se essencial para o neoliberalismo a capacidade de competir, pois esta é também uma característica da empresa. Deste modo, a governamentalidade ocorre a partir de um viés empreendedor, pois é por meio das relações entre a sociedade e o mercado que "se desenvolve a arte de governar, com uma capacidade cada vez mais sutil de intervenção, de inteligibilidade, de organização do conjunto de relações jurídicas, econômicas e sociais, do ponto de vista da lógica da empresa" (LAZZARATO, 2008, p.45).

Um dos objetivos da escolarização na lógica neoliberal, segundo Veiga-Neto (2000), é moldar ou criar o sujeito-cliente. O mercado torna-se assim um meio de governar os sujeitos na sociedade neoliberal. Como afirma o autor, a escola acaba assumindo um papel de orientar os futuros sujeitos-clientes a serem mais competitivos e competentes em suas escolhas de consumo. Diferença marcante esta, entre o liberalismo e o neoliberalismo, pois

enquanto no liberalismo a liberdade do mercado era entendida como algo natural, espontâneo, no sistema neoliberal a liberdade deve ser continuamente produzida e exercitada sob a forma de competição. Eis aí o ponto fulcral que irá fazer da escola uma instituição do maior interesse para o neoliberalismo (VEIGA-NETO, 2011, p. $38)$.

Deste modo, a instituição escolar torna-se fundamental para a garantia deste sujeito com tais características, pois pensando nos interesses da lógica neoliberal, que outra instituição poderia substituir a maquinaria escolar para produzir rapidamente este sujeito- 
cliente? (VEIGA-NETO, 2000). Neste sentido, pensamos com Foucault quando nos propõe outras compreensões para o neoliberalismo:

\begin{abstract}
Ao invés de compreendermos o liberalismo e o neoliberalismo como ideologias de sustentação e justificação do capitalismo e do capitalismo avançado (respectivamente), é mais produtivo compreendê-los como modo de vida, como ethos, como maneira de ser e de estar no mundo (VEIGA-NETO, 2011, p. 38).
\end{abstract}

A partir destas breves considerações, entendemos que nossas práticas enquanto professores de Matemática também corroboram, mesmo que por vezes sem intencionalidade, para a constituição de sujeitos que são efeitos do dispositivo ${ }^{1}$ neoliberal. O objetivo deste artigo é olhar, em especial, para as práticas lúdicas não somente como uma verdade naturalizada no campo da Educação Matemática, mas como produtoras de um sujeito lúdico que interessa à lógica do neoliberalismo. Para discutir esta questão, recorremos às teorizações foucaultianas sobre discurso e propomos alguns movimentos para analisar o material da pesquisa.

\title{
2 Apontamentos para uma análise do discurso lúdico na Educação Matemática
}

O discurso lúdico tem atravessado diferentes áreas do conhecimento, e especialmente no campo da Educação vem ganhando destaque por ser característico da "forma sujeito criança”. A Educação Matemática, por tratar também da educação de crianças, apodera-se deste discurso, e adquire força ao entrelaçar-se a outras verdades como a de que "a Matemática é a disciplina escolar mais difícil", ou ainda a de que "para aprender Matemática é preciso despertar o interesse do aluno", dentre outras. Deste modo, observamos uma formação discursiva em torno do lúdico, em que os modos de dizer e ver as condutas dos estudantes em relação a estas práticas sugerem modos de ser sujeito na contemporaneidade.

Para compreender o uso das práticas lúdicas e suas interlocuções com aspectos da sociedade neoliberal, analisamos os trabalhos publicados nos Anais do XI Encontro Nacional de Educação Matemática (ENEM), espaço que reúne pesquisadores e professores interessados em discutir a Matemática em suas interfaces com a Educação. Podemos inferir que os trabalhos publicados neste evento, dentre comunicações científicas, relatos de experiência e pôsteres, constituem um discurso que adquire estatuto de verdade no campo da Educação Matemática, pois como afirma Foucault,

\footnotetext{
${ }^{1}$ Entendemos um dispositivo como sendo uma "rede de relações que podem ser estabelecidas entre elementos heterogêneos: discursos, instituições, arquitetura, regramentos, leis, medidas administrativas, enunciados científicos, proposições filosóficas, morais, filantrópicas, o dito e o não dito" (CASTRO, 2009, p. 124).
} 
cada sociedade tem seu regime de verdade, sua "política geral" de verdade: isto é, os tipos de discurso que ela acolhe e faz funcionar como verdadeiros; os mecanismos e instâncias que permitem distinguir os enunciados verdadeiros dos falsos, [...] o estatuto daqueles que têm o encargo de dizer o que funciona como verdadeiro (FOUCAULT, 2011, p.12).

As "sociedades de discursos" objetivam produzir discursos que circulam em espaços fechados, conforme determinadas regras. Um destes espaços de grande visibilidade no campo em discussão é a Sociedade Brasileira de Educação Matemática (SBEM), onde ocorre a maior produção/circulação de discursos sobre o ensino e aprendizagem da Matemática no âmbito nacional, e que estão centrados na forma de discurso científico. A SBEM promove Encontros Nacionais e Seminários Internacionais sendo que o ENEM, organizado a cada três anos, é o evento nacional que conta maior número de trabalhos inscritos e de participantes. Os anais analisados nesta pesquisa são referentes ao XI ENEM ocorrido em julho de 2013 na cidade de Curitiba/PR, intitulado Educação Matemática: Retrospectivas e Perspectivas. Este tema se deve ao fato dos 25 anos da criação da SBEM, comemorados pelo evento, que contou com 4047 inscritos.

Portanto, considerando o ENEM como um lugar que comporta uma diversidade de sujeitos que possuem a função de dizer o "verdadeiro" sobre a Educação Matemática, os anais do ENEM de 2013 constituíram o material de análise da Dissertação de Mestrado: O lúdico na Educação Matemática: Efeitos na constituição do sujeito infantil contemporâneo (SARTORI, 2015). Para a Dissertação foram analisados 24 trabalhos na modalidade Comunicação Científica, 23 Relatos de Experiência e 7 Pôsteres, num total de 54 trabalhos, os quais foram lidos com devida atenção e extraídos os fragmentos para análise. Entretanto, neste artigo apresentamos as enunciações de 12 destes trabalhos, sendo que algumas delas não foram utilizadas na Dissertação, pois uma releitura do material possibilitou-nos outro olhar, com foco nos aspectos do neoliberalismo. Destas leituras, observamos quais eram as justificativas mais recorrentes para o uso do lúdico e a partir daí selecionamos alguns excertos para exemplificá-las.

Para a escolha dos trabalhos, consideramos ser mais conveniente selecioná-los conforme a modalidade: comunicação oral, exposição, relato de experiência e pôster dos diferentes eixos. Como critério de seleção, utilizamos, primeiramente, a busca pelos títulos, devido a grande quantidade de trabalhos. Ao fazer uma leitura rápida de todos, foram escolhidos 121 que abordavam a questão do lúdico especificamente. Ainda, foi feita uma escolha pelos trabalhos que apresentavam justificativas para o uso do lúdico apontando implicações para o ensino de Matemática ou para os significados que eram dados a esta 
prática. Neste último recorte foram analisados aqueles que tratavam especificamente da infância, considerando os que se referiam aos Anos Iniciais e Finais do Ensino Fundamental.

Ao olhar para este material com as lentes foucaultianas, entendemos que "os discursos não são resultado da combinação de palavras que representaram as coisas do mundo" (VEIGA-NETO, 2007, p. 93), eles estão apoiados em conjuntos de signos, o que não significa que sejam somente signos, elementos que remetem a conteúdos ou representações. "O que fazem é mais que utilizar esses signos para designar coisas. É esse mais que os tornam irredutíveis à língua e ao ato da fala. É esse "mais" que é preciso fazer aparecer e que é preciso descrever" (FOUCAULT, 2008, p.55). Para Foucault (2008, p. 132), o discurso pode ser entendido como

\begin{abstract}
um conjunto de enunciados, na medida em que se apoiem na mesma formação discursiva; ele não forma uma unidade retórica ou formal, indefinidamente repetível e cujo aparecimento ou utilização poderíamos assinalar (e explicar, se for o caso) na história; é constituído de um número limitado de enunciados para os quais podemos definir um conjunto de condições de existência.
\end{abstract}

Deste modo, podemos inferir que o discurso lúdico no campo da Educação Matemática é constituído por diversos enunciados. Além disso, um enunciado, segundo Foucault (2008), é constituído por enunciações. Nesta perspectiva, é necessário compreender os conceitos de enunciado, enunciação e formação discursiva de que trata o filósofo, pois estes aparecem em quase todas as formulações sobre discurso em suas obras.

A definição de enunciado se dá pela condição de existência que pode aparecer em unidades como frases, proposições, atos de linguagem. No entanto, o enunciado não se confunde com estes, pois, além disso, ele é um acontecimento. O termo enunciado é utilizado por Foucault, além de outros aspectos, para diferenciá-lo do todo, dos conjuntos de discursos. O enunciado é visto "como um grão que aparece na superfície de um tecido de que é o elemento constituinte; como um átomo do discurso" (FOUCAULT, 2008, p. 90).

Já uma enunciação se dá sempre que um conjunto de signos é emitido, é também um acontecimento, mas que não se repete, ao contrário do enunciado. Deste modo, um enunciado pode ser composto por múltiplas enunciações. Como nos explicou Foucault (2008), quando uma pessoa diz algo, podemos tomar esta fala como uma enunciação. Se outra pessoa diz o mesmo e ao mesmo tempo, avaliamos que existem duas enunciações, considerando assim sua singularidade. Neste entendimento, consideramos os excertos extraídos do material empírico como enunciações, as quais compõem o enunciado em questão.

Não cabe aqui buscar o sentido último ou oculto do enunciado, senão é como se quiséssemos desvelar uma verdade que "o" autor do discurso buscou manifestar, mas como 
sugeriu Foucault, devemos apenas ficar no nível das coisas ditas. Desta forma, não buscamos o que estaria "por trás" dos enunciados, suas significações ocultas, mas, simplesmente o que está dito e os efeitos que dele advém.

Assim, os enunciados sobre o lúdico fazem parte de uma formação discursiva, em que se foi produzindo condições de possibilidades para falar dos seus usos na escola, pelos documentos e pelas pesquisas acadêmicas, em determinado tempo e lugar. Portanto, consideramos que analisar o discurso da Educação Matemática a partir dos anais do XI ENEM é uma operação sobre estes documentos, ordenando e identificando elementos, “fazendo-os verdadeiros 'monumentos"”. É perguntar: "por que isso é dito aqui, deste modo, nesta situação, e não em outro tempo e lugar, de forma diferente?” (FISCHER, 2001, p. 205). Como aponta Foucault (2008), a partir de uma forma de fazer história em nossos tempos, os documentos são transformados em monumentos.

Sendo assim, estas ferramentas de análise propunham considerar o que é dito, ou o que foi dito, como um acontecimento, pois o dito instaura uma realidade discursiva. Por isso os sujeitos e os objetos são constituídos discursivamente, por meio do que vem sendo dito sobre eles, ou nas palavras de Foucault (2008, p.55), os discursos são constituídos por "práticas que formam sistematicamente os objetos de que falam". O sujeito não seria, portanto, a origem do discurso, mas um produto deste.

Neste sentido, o discurso como conjunto de enunciados é uma ferramenta de análise das formas de saber que definem o sujeito. Além disso, ao considerá-lo como prática, o discurso combinado com o poder, produz identidades. As relações de poder que perpassam a sociedade, tanto nas questões da governamentalidade do Estado quanto nas simples relações cotidianas, são permeadas e constituídas por discursos, como afirma Foucault, e os discursos são também estratégias de poder: “o poder é algo que funciona através do discurso, porque o discurso é, ele mesmo, um elemento em um dispositivo estratégico de relações de poder" (FOUCAULT, 2009, p. 465). Neste sentido, buscando compreender as relações de poder que atravessam a escola, em especial as aulas de Matemática, optamos por utilizar as ferramentas advindas da Análise do Discurso na perspectiva foucaultiana.

É neste sentido que este trabalho propõe pensar as interlocuções entre as enunciações que remetem ao uso do lúdico nas aulas de Matemática e as identidades que são efeitos do dispositivo neoliberal. Por meio da análise do discurso é possível mostrar os mecanismos e as relações de poder que atuam nessa produção, pois os enunciados que compõem um discurso em sua materialidade, contribuem na produção dos sujeitos. Como evidenciou Foucault, o 
sujeito é sempre um efeito discursivo, imerso em práticas discursivas, o discurso é uma ferramenta que permite subjetiva-los pelo seu exterior.

\title{
3 O sujeito lúdico e a lógica neoliberal: alguns entrelaçamentos
}

O dispositivo neoliberal constituído por práticas, instituições, regras, modos de governar, etc. atua em suas linhas de força na produção de uma forma de sujeito que possui algumas características específicas, conforme apontamos a partir dos estudos na perspectiva foucaultiana. Deste modo, nos questionamos sobre as práticas lúdicas utilizadas por professores de Matemática: Quais as justificativas atribuídas por eles à importância do lúdico? Quais as especificidades das identidades que estão sendo forjadas pelo discurso lúdico? Como o sujeito lúdico é capturado pelo dispositivo neoliberal? Para responder tais questões elencamos algumas enunciações provenientes dos trabalhos publicados nos anais do XI ENEM. Vejamos primeiramente o que dizem três destas pesquisas:

\begin{abstract}
A aprendizagem depende em grande parte da motivação: as necessidades e os interesses da criança são mais importantes que qualquer outra razão para que ela se ligue a uma atividade e da confiança na sua capacidade de construir uma ideia própria sobre as coisas, assim como exprimir seu pensamento com convicção são características que fazem parte da personalidade integral da criança (DALARMI, 2013 , p. 3, grifos nossos).
\end{abstract}

Nas atividades desenvolvidas, foram avaliadas as estratégias de resolução adotadas pelos estudantes, foi observado que as atividades desenvolvidas permitem mais autoconfiança e auto segurança ao aluno, e a Matemática torna-se mais prazerosa (NASCIMENTO; RODRIGUES, 2013, p. 11, grifos nossos).

Assim, os jogos podem ser usados na Educação Matemática por estimular e desenvolver a habilidade de a criança pensar de forma independente, contribuindo para o seu processo de construção de conhecimento lógico matemático (MACHADO; SILVA; CIABOTTI, 2013, p.4, grifos nossos).

No primeiro excerto, fica evidenciada a importância que os autores atribuem à motivação e ao interesse por parte do aluno para que a aprendizagem se efetive. Por se tratar de uma pesquisa que defende o uso de jogos nas aulas de Matemática, a capacidade do aluno de construir suas próprias ideias, bem como ter convicção delas, pode ser entendida como uma conduta desejada pelos professores e uma característica do sujeito lúdico. Do mesmo modo, os autores do segundo excerto apontam a necessidade da autoconfiança e auto segurança que podem ser garantidas a partir das atividades lúdicas. Pensar de forma independente é outro aspecto evidenciado como importante na construção de conhecimentos matemáticos, propiciado também pelos jogos. Estas características se entrelaçam às de um sujeito neoliberal, empreendedor de si mesmo. 
Selecionamos ainda as enunciações abaixo que apontam para uma aprendizagem mais independente, onde o aluno é sujeito ativo na construção do conhecimento. Além disso, destaca-se a importância da liberdade de tomada de decisões por parte do aluno. Tais aspectos são destacados por Veiga-Neto (2000) como necessários ao sujeito-cliente, que deve ter a liberdade de escolha e de expressar seus desejos. Ou como aponta Hamann (2012, p. 101), “o homo economicus neoliberal é um "átomo" de interesse próprio, livre e autônomo, plenamente responsável por navegar pelo campo social utilizando cálculos de escolha racional e custo-benefício".

Assim sendo, a característica do projeto, basicamente, é adotar metodologias que tornem o educando mais ativo na construção do seu conhecimento, utilizando recursos didáticos diversificados com o intuito de motivar o aprendizado e despertar a atenção e a curiosidade destes (FERREIRA, MARQUES, 2013, p. 3, grifos nossos).

$\mathrm{O}$ ato de brincar pertence à natureza espontânea da criança e é benéfico por estar centrado no prazer, despertando as emoções, sensações e a necessidade de se socializar com o outro, desenvolve o exercício de liberdade, quando viabiliza a criança o significado de arriscar, criar, progredir, interagir, representar, construir, entre outras ações, que remetem a uma constante evolução (STAL; CAMARGO, 2013, p.1, grifos nossos).

As enunciações apontam outros aspectos atribuídos aos alunos como a vontade de competir. Destacamos três enunciações que remetem à importância da competição, do desejo de vencer os desafios propostos por meio dos jogos, pois na lógica neoliberal a "liberdade é definida, condicionada e confinada no interior de uma forma de assujeitamento caracterizada pela crescente competição" (HAMANN, 2012, p. 201). Neste sentido, propomos esta interlocução visto que um dos objetivos do neoliberalismo é fazer com que a competição entre os sujeitos pareça natural e necessária.

Após essa explicação os alunos estavam mais tranquilos, cada dupla jogava um contra o outro, o interesse de ganhar despertou o desejo de resolver as equações (NASCIMENTO; RODRIGUES, 2013, p. 8, grifos nossos).

O jogo favorece o desenvolvimento da criatividade, do senso crítico, da participação, da competição sadia, da observação, das várias formas de uso da linguagem e do prazer em aprender (RIBEIRO; GOULART, 2013, p. 4, grifos nossos).

No entanto, observamos que no momento em que os alunos jogavam, ficavam tão centrados nas regras, na vontade de ganhar, que esqueciam que estavam aprendendo matemática (VERGUTZ; KIELBA; ALVES; COLOMBO, 2013, p. 10, grifos nossos).

Conforme os trabalhos analisados, os alunos por vezes não tem o desejo de aprender, e este aspecto seria fundamental para o aprendizado. Observamos nas propostas dos trabalhos que o desejo em saber mais, em entender o conteúdo proposto, surge quando o professor 
busca novas maneiras de ensinar, atrativas e que seduzem o aluno. Neste sentido, as atividades lúdicas são consideradas como a principal alternativa utilizada pelos professores com o objetivo de instigar o desejo de aprender Matemática. As duas enunciações a seguir exemplificam esta justificativa que aparece com recorrência nos trabalhos.

\footnotetext{
Uma das estratégias adequadas para despertar o gosto pela matemática é pelo desenvolvimento de atividades lúdicas [...] Representa uma ferramenta em potencial para aproximar crianças, jovens e adultos, além de despertar o desejo de saber mais (ZIECH et al., 2013, p. 3, grifos nossos).

O professor necessita pensar uma maneira de trabalhar com os conteúdos em sala de aula de modo que chame a atenção, ou seja, uma educação que promove mudanças e desperta $o$ desejo e a curiosidade de seus alunos (JACOBSEN; MAFFEI; SPEROTTO, 2013, p. 2, grifos nossos).
}

Bauman (2008; 2009) aponta o desejo como algo que move a sociedade contemporânea, a qual denominou de sociedade do consumo. A organização da vida do sujeito consumidor é também guiada pela sedução, por desejos e vontades voláteis. Nas palavras do autor, "o consumismo é um tipo de arranjo social resultante da reciclagem de vontades, desejos e anseios humanos rotineiros, permanentes" (BAUMAN, 2008, p. 41).

Para Bauman (2008), essa cultura do consumo na contemporaneidade principalmente neste final de século, não está somente ligada ao fato de adquirir bens e mercadorias, mas também à criação de desejos sempre constantes, desejos sobre o que não se tem, ou seja, esse desejo é sempre ativado pela ausência de algo que falta e nunca é satisfeito. Desta forma, o sujeito sempre está diante da instabilidade de seus desejos e a insaciabilidade de suas necessidades, buscando o prazer de ter o que deseja. Assim, podemos dizer que o consumismo é resultante da produção de vontades, desejos e anseios, os quais se tornam a principal força propulsora e operativa da sociedade.

Portanto, na concepção de Bauman (2008) é o desejo, a vontade, a necessidade de adquirir e descartar bens que constitui o sujeito do consumo. Ou em termos foucaultianos, pensamos que é por meio do desejo que se governam os indivíduos desta sociedade, regular seus desejos é o que garante o controle da sociedade do consumo que, juntamente a outros aspectos, produz a sociedade neoliberal.

As enunciações referentes ao desejo exemplificadas na análise apontam para as seguintes justificativas atribuídas pelos autores dos trabalhos para a utilização de atividades lúdicas nas aulas de Matemática: a criança deseja brincar; ela precisa ter o desejo/vontade de aprender Matemática; a criança tem desejo de vencer, de superação no jogo ou na atividade proposta. Entrelaçado à questão do desejo, observamos nos excertos o prazer que o lúdico 
proporciona, pois alguns autores compreendem o desejo e o prazer como aspectos imbricados nas práticas lúdicas.

O lúdico como sinônimo de algo prazeroso aparece na maioria dos trabalhos analisados. Assim, o enunciado que diz da importância de se aprender com prazer, também é bastante recorrente. Os autores apontam que é necessário que se dê importância às atividades que despertem o prazer no cotidiano da criança, inclusive na escola. É notória por parte do professor esta preocupação em ensinar Matemática de maneira que o aluno sinta prazer em aprender, e assinalam as atividades lúdicas como principal recurso que seduz a criança pelo prazer que proporciona. Estas enunciações se entrelaçam também ao enunciado que aponta para a dificuldade da disciplina. Como ressaltado nos excertos abaixo, o uso pedagógico do lúdico é importante e necessário, pois permite uma aprendizagem prazerosa dos conteúdos matemáticos.

\footnotetext{
A Matemática é vista como uma disciplina amedrontadora por muitos alunos, mas eles não sabem que dentro desse medo, a disciplina pode apresentar espaço para o prazer, para descobertas e para criatividade. Uma forma de despertar essa motivação e o prazer é a inserção de jogos no ensino (NASCIMENTO; RODRIGUES, 2013, p. 1 , grifos nossos).
}

Sendo assim, acreditamos que as atividades desenvolvidas no projeto Clube de Matemática proporcionam aos alunos participantes uma aprendizagem mais natural e prazerosa do conteúdo matemático (SALAZAR; CEDRO, 2013, p. 2, grifos nossos).

Segundo os autores dos excertos acima, ao elaborar estratégias para garantir o aprendizado dos alunos em Matemática devemos considerar primeiramente o que pode lhes proporcionar prazer, pois seduzidos por este, o ensino se torna mais eficaz. Assim, por intermédio do lúdico os professores esperam transformar o ensino de Matemática nas escolas, pois consideram que desta maneira, este prazer, muitas vezes ausente das salas de aula, ainda pode ser acionado. Outro aspecto deste ensino, por meio do prazer, é que este pode estar associado à vitória quando o lúdico é utilizado com o viés competitivo.

A busca pelo prazer, assim como pelo desejo, perpassa a vida dos sujeitos consumidores, e é característica desta sociedade, de uma "cultura consumista como a nossa, que favorece o produto pronto para uso imediato, o prazer passageiro, a satisfação instantânea, resultados que não exijam esforços prolongados, receitas testadas" (BAUMAN, 2004, p.11). Assim, o mercado produz cada vez mais artefatos que proporcionem prazer aos seus compradores, no momento da compra ou do uso do produto. Porém, a finalidade é produzir prazeres instantâneos, para que o consumidor possa desejar outros prazeres, o que 
parece condizer, mesmo com os aspectos específicos de cada situação, com o objetivo de produzir um aluno que sinta prazer no momento da aprendizagem.

Aprendendo com prazer o aluno satisfaz seus desejos. A satisfação é uma das características que se associa ao desejo e a vontade. Nos excertos a seguir, os autores enfatizam que a criança brinca para satisfazer suas necessidades. A satisfação propiciada pela brincadeira é um fator relevante considerado por educadores quanto aos seus usos na escola. Do mesmo modo como o aluno se sente satisfeito quando brinca, esta satisfação deve estar presente quando aprende Matemática, pois a aprendizagem desta disciplina não deve ser algo que ocorra de forma que seja um sacrifício. Portanto, a satisfação dos alunos ocorre quando participam de atividades lúdicas que tornam a Matemática mais atrativa, interessante e curiosa. As enunciações a seguir mostram como a questão da satisfação é essencial para o aprendizado, na concepção dos professores.

[...] é possível ensinar matemática por meio da ludicidade em um ambiente de ensino-aprendizagem que instigue o interesse do aluno, promovendo a curiosidade e a satisfação em aprender (OLIVEIRA; VALERIANO, 2013, p. 1, grifos nossos).

Ao fim de cada atividade que foi realizada, os alunos nos relataram a satisfação em participar daquelas atividades e que a matemática estava mais atrativa (OLIVEIRA; VALERIANO, 2013, p. 9, grifos nossos).

Entretanto, alguns trabalhos apontam que esta satisfação propiciada pelo lúdico é momentânea, ou seja, o aluno logo se cansa de brincar e continua em busca de satisfazer outros desejos, por outros meios, ou até outras atividades lúdicas. $\mathrm{O}$ aluno, sempre a procura de novidades, na busca por concretizar outras vontades, nunca está satisfeito. O jogo ou a brincadeira são vistos pelos alunos, por vezes, como monótonos e repetitivos, pois se "cansam rápido" por estarem realizando por determinado tempo a mesma atividade. Deste modo, é preciso precaução por parte do professor, segundo os autores, para que o lúdico não perca sua característica de atividade que produza satisfação. Este aspecto pode se aproximar da satisfação na sociedade de consumidores, que deve ser somente uma experiência momentânea e não deve durar muito tempo (BAUMAN, 2008). Como mencionam os autores dos excertos, as atividades lúdicas garantem a satisfação da criança, entretanto esta satisfação não é, por vezes, duradoura. Neste sentido é que sinalizamos estes excertos:

A proposta do Euclidean é ser um jogo que possa: 1) envolver o aluno, fazendo com que se sinta atraído e interessado em jogar; Também procura motivar o aluno a prosseguir, sem que o jogo se torne chato e repetitivo (FLORET, 2013, p. 8, grifos nossos).

Outra dificuldade enfrentada em aulas com jogos digitais é relatada por P3, que afirma: "Durante a aplicação desse jogo pude verificar que os alunos se 
entusiasmam muito no início, mas logo se cansam do jogo e já querem mudar para outro" (CARDOSO; OLIVEIRA; KATO, 2013, p. 10, grifos nossos).

Segundo Bauman (2008), nossas necessidades não podem ter fim, procuramos sempre novas mercadorias, impulsionados e atraídos incessantemente por satisfação. Se não tivermos mais nada a desejar, se nos conformarmos com o que temos, não procurarmos algo novo para nos satisfazer, como aponta o autor, tal situação só pode receber um nome: "tédio". Estar em movimento é o que importa: obter, expor, descartar... é o que move esta sociedade, "não é a satisfação das necessidades que atormenta a pessoa, mas os tormentos dos desejos ainda não percebidos nem suspeitados que fazem a promessa ser tão tentadora” (BAUMAN, 1999, p. 90).

Elencadas tais enunciações, podemos inferir que as atividades lúdicas utilizadas para ensinar Matemática na escola acabam contribuindo para a produção de um sujeito lúdico que é moldado também nas tramas do neoliberalismo. Mesmo sendo por meio de micro relações, que por vezes não são percebidas pelos professores, estas práticas produzem condutas desejadas. Assim, a maquinaria escolar fabrica seus alunos-clientes-empreendedores de si, pois conforme aponta Saraiva (2015, p. 59), a racionalidade neoliberal

\begin{abstract}
não se encontra alojada numa suposta instância estatal, embora aí esteja condensada, mas capilarizada na sociedade, produzindo modos de ser, de estar e de compreender o mundo. A potência dessa capilarização está, justamente, na invisibilidade que confere a essa racionalidade, permitindo que penetre nos cantos mais recônditos da vida individual e social.
\end{abstract}

\title{
4 Considerações finais
}

As problematizações acerca dos efeitos do neoliberalismo na sociedade, em especial na escola, nos permitem problematizar práticas pedagógicas que parecem estar naturalizadas no discurso educacional. Do ponto de vista foucaultiano, entendemos que tais práticas estão associadas à governamentalidade que objetiva produzir sujeitos governáveis, assim, a escola é uma das instituições que fazem parte de uma "máquina de governamentalização" (BUJES, 2002, p.146) que articula eficientemente o saber e o poder. Segundo Foucault, este conceito está associado aos processos de constituição do sujeito, formando identidades, pois "são as 'práticas' concebidas ao mesmo tempo como modo de agir e de pensar que dão a chave de inteligibilidade para a constituição correlativa do sujeito e do objeto" (FOUCAULT, 2004, p. 238).

Neste sentido, a análise do discurso como ferramenta metodológica nos foi útil na medida em que identificamos no discurso lúdico o sujeito que está sendo produzido em 
consonância com o dispositivo neoliberal. Utilizamos como material de análise enunciações extraídas de trabalhos publicados nos anais do XI ENEM, que enfatizavam a importância do uso de atividades lúdicas nas aulas de Matemática. Destacamos que tais justificativas estão atreladas às necessidades estabelecidas pela sociedade neoliberal: a capacidade do sujeito construir suas próprias ideias e demonstrar convicção sobre elas; pensar de forma independente; ser sujeito ativo na construção do conhecimento; ter autoconfiança e auto segurança; tais aspectos contribuem para a constituição de um sujeito empreendedor de si mesmo. Além disso, destacamos a importância da liberdade de tomada de decisões por parte do aluno, que também caracteriza o sujeito-cliente, que possui liberdade de escolha. Apresentamos ainda as enunciações que remetem à importância da competição entre os sujeitos. Para concluir, os excertos mostram a importância de constituir desejo nos alunos, produzindo satisfação e prazer, características dos consumidores.

Com Foucault, permitimo-nos compreender as práticas escolares como tecnologias de poder e saber, constituídas por discursos, e como afirma Veiga-Neto (2000), podemos pensar a instituição escolar a partir de seus estudos, pois a escola é um lugar privilegiado para que novas tecnologias sejam inventadas e aplicadas. Portanto, pensamos ser possível problematizar o enunciado "é importante trabalhar com atividades lúdicas nas aulas de matemática", suspeitar desta "verdade", "sacudir a quietude com a qual a aceitamos" (FOUCAULT, 2008, p.31), e pensar nos sujeitos que estão sendo fabricados a partir dela.

\section{Referências}

BAUMAN, Z. Amor líquido: sobre a fragilidade dos laços humanos. Tradução de C. A. Medeiros. 1. ed. Rio de Janeiro: Zahar, 2004. 189 p.

BAUMAN, Z. Vida para consumo: a transformação de pessoas em mercadoria. Tradução de C. A. Medeiros. 1. ed. Rio de Janeiro: Zahar, 2008. 198 p.

BAUMAN, Z. Vida líquida. Tradução de C. A. Medeiros. 2. ed. Rio de Janeiro: Jorge Zahar, 2009. $210 \mathrm{p}$.

BUJES, M. I. E. Infância e Maquinarias. 1. ed. Rio de Janeiro: DP\&A, 2002. 286 p.

CARDOSO, V. C.; OLIVEIRA, S. R.; KATO, L. A. Percepção de professores sobre o uso de jogos digitais educativos em aulas de matemática. In: ENCONTRO NACIONAL DE EDUCAÇÃO MATEMÁTICA, 11., 2013, Curitiba. Anais... Curitiba: SBEM, 2013. p. 1-13.

CASTRO, E. Vocabulário de Foucault: um percurso pelos seus temas, conceitos e autores. Tradução de I. M. Xavier. 1. ed. Belo Horizonte: Autêntica, 2009. 477 p. 
COSTA, S. S. G. Governamentalidade neoliberal, teoria do capital humano e empreendedorismo.

Educação e Realidade, Porto Alegre, v. 34, n. 2, p. 171-186, 2009.

DALARMI, T. T. O uso de jogos nas aulas de matemática. In: ENCONTRO NACIONAL DE EDUCAÇÃO MATEMÁTICA, 11., 2013, Curitiba. Anais... Curitiba: SBEM, 2013. p. 1-14.

FERREIRA, D. S.; MARQUES, É. S. Adivinhações algébricas: um novo olhar sobre o ensino da Matemática. In: ENCONTRO NACIONAL DE EDUCAÇÃO MATEMÁTICA, 11., 2013, Curitiba. Anais... Curitiba: SBEM, 2013. p. 1-8.

FISCHER, R. M. B. Foucault e a análise do discurso em educação. Cadernos de Pesquisa, Fundação Carlos Chagas, n. 114, p. 197-223, nov. 2001.

FLORET, H. F. Euclidean: o jogo da combinatória. In: ENCONTRO NACIONAL DE EDUCAÇÃO MATEMÁTICA, 11., 2013, Curitiba. Anais... Curitiba: SBEM, 2013. p. 1-15.

FOUCAULT, M. A governamentalidade. In: Microfísica do Poder. Tradução de R. Machado. Rio de Janeiro: Ed. Graal, 1992. p. 277-293.

FOUCAULT, M. A Ordem do Discurso: aula inaugural do Collège de France, pronunciada em 2 de dezembro de 1970. Tradução de L. F. de A. Sampaio. 5. ed. São Paulo: Loyola, 1999. 79 p.

FOUCAULT, Michel. Ditos \& Escritos V: ética, sexualidade, política. Tradução de E. Monteiro; I. A. D. Barbosa. 1. ed. Rio de Janeiro: Forense Universitária, 2004. 392 p.

FOUCAULT, M. Ditos e Escritos III: estética: literatura e pintura, Música e Cinema. Tradução de I. A. D. Barbosa. 2. ed. Rio de Janeiro: Forense Universitária, 2009. 435 p.

FOUCAULT, M. A Arqueologia do Saber. Tradução de L. F. B. Neves. 7. ed. Rio de Janeiro: Forense Universitária, 2008. 238 p.

FOUCAULT, M. Microfísica do Poder. Tradução de R. Machado. 29ª reimpressão. Rio de Janeiro: Edições Graal, 2011. 296 p.

HAMANN, T. H. Neoliberalismo, governamentalidade e ética. Ecopolítica, São Paulo, n. 3, p. 99133, 2012.

JACONBSEN, D. R.; MAFFEI, L. Q.; SPEROTTO, R. I. Jogos eletrônicos: um artefato tecnológico para o ensino e para a aprendizagem In: ENCONTRO NACIONAL DE EDUCAÇÃO MATEMÁTICA, 11., 2013, Curitiba. Anais... Curitiba: SBEM, 2013. p. 1-14.

LAZZARATO, M. Biopolítica/bioeconomia. In: PASSOS, I. C. F. (Org.). Poder, Normalização e Violência: incursões foucaultianas para a atualidade. Belo Horizonte: Ed. Autêntica, 2008. p. 41-52.

MACHADO, A. A. R; SILVA, J. dos S.; CIABOTTI, V. Elaboração de jogo de fixação de aprendizagem em estatística para o nono ano do ensino fundamental. In: ENCONTRO NACIONAL DE EDUCAÇÃO MATEMÁTICA, 11., 2013, Curitiba. Anais... Curitiba: SBEM, 2013. p. 1-15.

OLIVEIRA, N. C. N.; VALERIANO, W. P. O. A atividade orientadora de ensino: o lúdico e o recurso didático como mediadores no processo de ensino-aprendizagem em matemática. In: ENCONTRO NACIONAL DE EDUCAÇÃO MATEMÁTICA, 11., 2013, Curitiba. Anais... Curitiba: SBEM, 2013. p. 1-10. 
RIBEIRO, C. E.; GOULART, A. O ensino de probabilidade por meio de jogos na educação de jovens e adultos. In: ENCONTRO NACIONAL DE EDUCAÇÃO MATEMÁTICA, 11., 2013, Curitiba. Anais... Curitiba: SBEM, 2013. p. 1-15.

NASCIMENTO, R. M. L. L. do.; RODRIGUES, L. T. S. O uso de jogos para o ensino da matemática. In: ENCONTRO NACIONAL DE EDUCAÇÃO MATEMÁTICA, 11., 2013, Curitiba. Anais... Curitiba: SBEM, 2013. p.1-12.

SALAZAR, G. A. A.; CEDRO, W. L. Ludo monetário: uma proposta de atividade orientadora de ensino. In: ENCONTRO NACIONAL DE EDUCAÇÃO MATEMÁTICA, 11., 2013, Curitiba. Anais... Curitiba: SBEM, 2013. p. 1-10.

SARAIVA, K. Novas geometrias no trabalho e na educação. In: KIRCHOF, E. R.; WORTMANN, M. L.; COSTA, M.V. (Org.). Estudos Culturais e Educação: contingências, articulações, aventuras, dispersões. Canoas: Ed. ULBRA, 2015. p. 57-72.

SARAIVA, Karla; VEIGA-NETO, Alfredo. Modernidade líquida, capitalismo cognitivo e educação contemporânea. Educação \& Realidade, Porto Alegre, v. 34, n. 2, 2009, p. 187-202.

SARTORI, A. S. T. O Lúdico na Educação Matemática Escolar: efeitos na constituição do sujeito infantil contemporâneo. 2015. 158f. Dissertação (Mestrado em Educação Científica e Tecnológica) Centro de Ciências Físicas e Matemática, Universidade Federal de Santa Catarina, Florianópolis, 2015.

STAL, J. Ç.; CAMARGO, J. A. Utilizando o bingo para aprender e ensinar matemática. In: ENCONTRO NACIONAL DE EDUCAÇÃO MATEMÁTICA, 11., 2013, Curitiba. Anais... Curitiba: SBEM, 2013. p. 1-10.

VEIGA-NETO, A. Educação e governamentalidade neoliberal: novos dispositivos, novas subjetivações. In: PORTOCARRERO, V.; CASTELO BRANCO, G. Retratos de Foucault. Rio de Janeiro: Ed. Nau, 2000. p. 179-217.

VEIGA-NETO, A. Foucault \& a Educação. 1. ed. Belo Horizonte: Autêntica, 2007. 160 p.

VEIGA-NETO, A. Governamentalidades, neoliberalismo e educação. In: BRANCO, G. C.; VEIGANETO, A. V. Foucault: filosofia \& política. Belo Horizonte: Ed. Autêntica, 2011. p. 37-52.

VERGUTZ, B. C. et al. Registros de Representação Semiótica e jogos: Possibilidades para o ensino de matemática. In: ENCONTRO NACIONAL DE EDUCAÇÃO MATEMÁTICA, 11., 2013, Curitiba. Anais... Curitiba: SBEM, 2013. p. 1-13.

ZIECH, R. O. et al. O lúdico como recurso didático-pedagógico no ensino-aprendizagem da matemática. In: ENCONTRO NACIONAL DE EDUCAÇÃO MATEMÁTICA, 11., 2013, Curitiba. Anais... Curitiba: SBEM, 2013. p. 1-9.

Submetido em Maio de 2016. Aprovado em Novembro de 2016. 